\title{
Performing Orders: Speech Acts, Facial Expressions and Gender Bias
}

\author{
Filippo Domaneschi \\ University of Genoa, DISFOR - Department of Educational Sciences, \\ Psychology Unit, Corso Podestà, 2, Room ${ }_{3} \mathrm{C}_{3}$ \\ Director of the Laboratory of Psychology of Language, 16128 Genova, Italy \\ filippo.domaneschi@unige.it
}

Marcello Passarelli

University of Genoa, DISFOR - Department of Educational Sciences, Psychology Unit, Corso Podestà, 2, Room 3C 3 , 16128 Genova, Italy

\section{Luca Andrighetto}

University of Genoa, DISFOR — Department of Educational Sciences, Psychology Unit, Corso Podestà, 2, Room ${ }_{3} \mathrm{C}_{3}, 16128$ Genova, Italy

\begin{abstract}
The business of a sentence is not only to describe some state of affairs but also to perform other kinds of speech acts like ordering, suggesting, asking, etc. Understanding the kind of action performed by a speaker who utters a sentence is a multimodal process which involves the computing of verbal and non-verbal information. This work aims at investigating if the understanding of a speech act is affected by the gender of the actor that produces the utterance in combination with a certain facial expression. Experimental data collected show that, as compared to men, women are less likely to be perceived as performers of orders and are more likely to be perceived as performers of questions. This result reveals a gender bias which reflects a process of women's subordination according to which women are hardly considered as holding the hierarchical social position required for the correct execution of an order
\end{abstract}

\section{Keywords}

speech act - illocutionary force - facial expression - gender bias 


\section{1 \\ Speech Acts and Facial Expressions}

\subsection{Speech Acts}

Since the seminal work of John Austin (1962), language scientists recognize that the business of a sentence is not only to describe some state of affairs but also to perform other kinds of speech acts (e.g., ordering, suggesting, asking, recommending, etc.).

According to the Speech Act Theory (Austin 1962; Searle 1975), every speech act can be described by three levels. Consider for instance the following speech act:

\section{(1) Shoot him!}

The locutionary act is the act of saying something: the actual production of an utterance with a full meaning, and a particular syntactic and phonological realization - e.g., "Shoot Mark!".

The illocutionary act is the act performed in saying something: it is the action performed by uttering a certain sentence and it is characterized by the illocutionary force of the utterance, i.e. its intended socially valid verbal action - e.g., (1) can be uttered with the force of an 'order'.

The perlocutionary act is the act performed by saying something: the actual effect produced by a speech act, like persuading, convincing, scaring, getting someone to do or realize something — e.g., (1) might persuade the addressee to shoot someone.

Thus, the very same proposition can be associated with different illocutionary forces, i.e., it can perform different actions in different contexts. In the last decades, linguists and psycholinguists have faced the problem of explaining how language users recognize the kind of speech act performed by a speaker uttering a sentence in a particular context, by investigating the role played by the illocutionary force-indicating devices (IFIDs; Searle \& Vanderveken, 1985), i.e., all the linguistic elements that indicate or delimit the illocutionary force of an utterance. Typically, three main types of linguistic IF IDs have been considered: a) lexical indicators, such as expressions as "Attention!" or "Warning” that indicate the act of advising; b) syntactic indicators like the verbal mode, and c) prosodic indicators like the intonation contour, the pitch of accents and other suprasegmental factors.

\subsection{Facial Expressions as Non-Verbal IFIDs}

An IFID shows how an utterance is to be taken, i.e. what speech act the speaker is performing while uttering a sentence. Research in linguistics and psycholinguistics has so far produced a rich literature on the linguistic IFIDs (Searle \& 
Vanderveken, 1985). Conversely, although it is commonly recognized that the comprehension of a speech act depends also on non-verbal illocutionary force indicating devices (Searle, 1975), research on the non-verbal IFIDs is still fragmented at a theoretical level and lacking empirical investigations.

In the field of multimodal communication, several psychological and linguistic studies revealed the importance of the different functions played by non-verbal signals in verbal interactions (e.g., Esposito et al., 2010), such as the role of gaze in the conversational turn-taking system (Oertel et al., 2012) and as a syntactic signal (Poggi \& Pelachaud, 2001) or the interpretation of the mouth region in lying (Ekman \& Friesen, 1978) and in phonemes articulation (McGurk \& McDonald, 1976).

Besides the study of gaze or of specific parts of the face, since the seminal work of Ekman and Friesen (1978), face as a whole has been considered with respect to the expression of emotions. These scholars developed the Facial Action Coding System (FACS), where the muscular activity is coded in the form of a combination of Action Units (AUs), each representing a basic facial muscular movement. This approach allows to efficiently and reliably describe complex facial expressions in terms of combinations of AUs. In the study of facial communication, the FACs has then contributed to develop a research line on multimodal communication aimed at investigating, for instance, how facial expressions together with head movements are used in linguistic communication to rule the turn-taking system, as a mean for the feedback-production (Allwood, Cerrato, Jokinen, Navarretta \& Paggio, 2005) - e.g., agreeing, confirming, disconfirming, following — with a syntactic and dialogic function (Pelachaud, Carofiglio et al., 2002) or in relation with the prosodic realization (Pelachaud \& Prevost, 1994).

Recently, Domaneschi, Passarelli and Chiorri (2017) in a series of production and comprehension studies provided first evidence supporting the idea that the upper-face AUs constitute a non-verbal IFID. In particular, they showed that in language comprehension there are specific combinations of upper-face AUs that, with different degrees of compatibility, are associated with three prototypical illocutionary forces (see Table 1): orders, assertions, and questions.

Their data revealed that a sentence uttered in a context is more likely to be interpreted as an order when it is jointly produced with the $\mathrm{AU}_{4+5}$, as an assertion with AUo (i.e., Null AU), and as a question with $\mathrm{AU}_{2}$ and $\mathrm{AU} 1+4$, while $\mathrm{AU}_{4+7}$ constitutes a facial expression equally associated with orders and questions (see Fig. 1).

Despite the relevance of this seminal work, it is plausible to imagine that this peculiar pattern of associations between illocutionary forces and upper-face 
TABLE 1 Illocutionary force, sentence type and examples of assertions, questions and orders

\begin{tabular}{lll} 
Speech act & Sentence type & Example \\
\hline Assertion & Declarative & John takes the bus \\
Question & Interrogative & Does John take the bus? \\
Order & Imperative & John, take the bus! \\
\hline
\end{tabular}
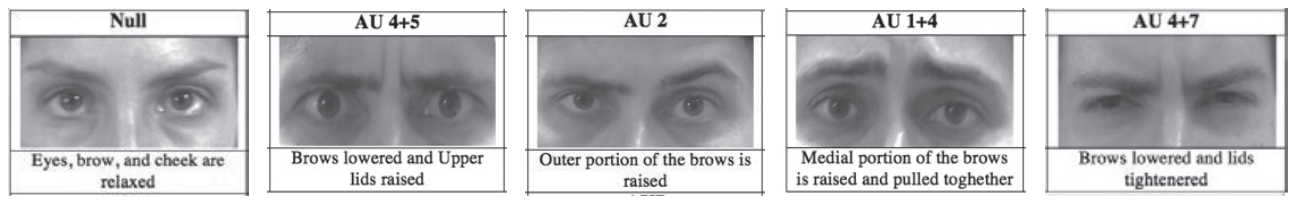

FIGURE 1 Upper face AUs that constitute non-verbal IFIDs for assertions (AUo), questions $\left(\mathrm{AU}_{2}, \mathrm{AU}_{1+4}\right)$, orders $\left(\mathrm{AU}_{4+5}\right)$, plus the ambiguous $\mathrm{AU}_{4+7}$ (Domaneschi et al., 2017)

AUs would not constantly emerge, but could be affected for instance by individual characteristics of the actor that performs the speech act. In particular, in the present paper we aim to explore whether the gender of the actor could affect the way in which perceivers associate a speech act with the corresponding actor's AU. Below are explained our main hypotheses and the theoretical rationale underlying them.

\subsection{Research Question and Predictions}

The present study takes a first step towards an empirical investigation of the role of gender as a potential predictor for the association speech act/facial expression. The main research question at stake is: is the understanding of a speech act affected by the gender of the actor that performs the speech act in combination with a certain facial expression?

Our main prediction is that perceivers would be less likely to associate the illocutionary force of the order with the corresponding facial expression (i.e., $\left.A U_{4}+5\right)$ when it is displayed by women rather than by men. This key prediction results from an integration of the linguistic literature on speech acts and the social psychological research on gender roles and stereotypes.

First, according to the Speech Act Theory, assertions and questions, on the one hand, and orders, on the other, possess different preparatory conditions (Searle, 1975), as they presuppose different hierarchical relations between the 
speaker and the addressee: while assertions and questions admit an equal status of the interlocutors, a felicity condition (Austin, 1962) of an order is that there is a hierarchical superiority of the speaker on the addressee.

Second, the social-role theory (e.g., Eagly, 1987; see also Eagly, Wood, \& Diekman, 2000) posits that gender stereotypes arise from the characteristics associated with the roles that men and women typically fill in a given society. In most western societies, men hold positions that are viewed as more powerful and agentic than those held by women, whereas women occupy positions that are perceived as more subordinate and passive than those occupied by men (e.g., Eagly \& Wood, 1999; Fiske, 1993). These perceptions result in gender stereotypes that are commonly endorsed both by men and women (e.g., Cuddy, Fiske, \& Glick, 2007) and that portray men as dominant, agentic, or goal oriented and women as interdependent, affiliative, and dependent from others (Eagly \& Steffen, 1984).

Interestingly, a number of studies (e.g., Hess, Adams, \& Kleck, 2004; Plant, Kling, \& Smith, 2004) revealed that these gender stereotypes deeply shape the interpretation of others' emotional expressions. For example, Plant and colleagues (2004) showed that the same facial expressions were interpreted as conveying different emotions depending on the poser's gender. In particular, the male poser's expression was judged as higher on anger and contempt two emotions stereotypically more associated with men than women (Plant, Hyde, Keltner, \& Devine, 2010) - than the identical female poser's expression.

Drawing from these studies, our main prediction is that a gender effect would emerge when considering the association of the act of ordering with the facial expression that is typically interpreted as a marker of orders, i.e. $\mathrm{AU}_{4+5}$. In particular, we expect that, independently on the gender of the actor, AU $4+5$ would be mostly associated with orders as compared to assertions and questions. Such an association, however, is less likely to occur when the performer of the speech act is a woman rather than a man, in virtue of the fact that women are typically perceived as subordinated and, as such, are hardly considered holding the hierarchical social position required for the execution of an order. Conversely, concerning assertions and questions, we expect that, consistent with Domaneschi and colleagues (2017), AUo should be mostly associated with assertions and $\mathrm{AU}_{2}$ and $\mathrm{AU}_{1}+4$ with questions. However, since these speech act types do not involve a preparatory condition that entails a hierarchical superiority of the speaker on the addressee, we should not observe a gender effect on these speech act/facial expressions pairs.

Importantly and consistent with the previous literature on gender stereotypes (see e.g., Cuddy et al., 2007), we assumed that this pattern of associations would not be influenced by the gender of the perceivers. 
We investigated the above hypotheses in a comprehension study in which participants were asked to select among a list of sentences where the same content was conveyed as an order, a question, or an assertion, the one considered most compatible with a picture representing an upper-face facial expression. In particular, we considered male and female actors performing the five upper-face AUs identified by Domaneschi and colleagues (2017) as non-verbal IFIDs for assertions, questions and orders.

\section{$2 \quad$ Experiment}

\subsection{Method and Design}

The experiment was carried out online with 195 Italian native-speakers using Limesurvey $2.05^{+}$. Participation was voluntary, and participants received no compensation. Only data from participants who completed at least half of the task were retained for analysis $(N=152 ; 105$ females; age $=27.17 \pm 8.24$, range $=$ 18-64), for a total of 5972 observations.

The task consisted of 40 items. In each item, a picture of the upper-face of an individual was used as a stimulus. Together with the picture, participants were presented with five sentences. They were asked to select the sentence that best matched the picture, that is the sentence that they considered the one pronounced by the actor. They had to commit their answer before proceeding to the following item, and could not correct previous responses. An item example is shown in Fig. 2.

As above mentioned, each set of sentences had the same propositional content, but different illocutionary force. More specifically, each of them contained an assertion, a question, an order, and two 'filler' illocutions that varied across items (e.g., a vow and an advice for one item, a suggestion and a bet on another, and so on). The illocutionary force of each sentence was linguistically expressed by using an explicit performative verb. For example, the list expressing the proposition "Marco studia" (lit. Eng. tr. Marco studies) was:

(4)

Italian

Assertion: So che Marco studia

Question: Una domanda: Marco studia?

Order: Ł̀ un ordine: Marco studia!!

\section{English Translation}

Assertion: I know that Marco studies

Question: A question: does Marco study?

Order: This is an order: "Marco study!" 


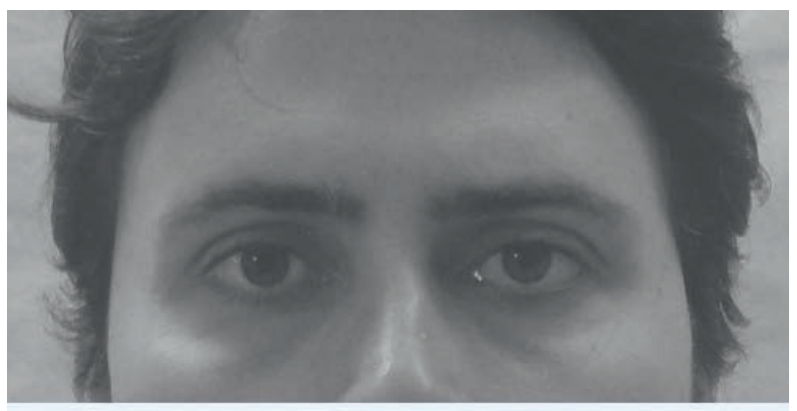

Scegliere solo una delle seguenti voci

Ė un ordine: "Arriverai puntuale!!"

Mi fa piacere che arriverai puntuale

So che arriverai puntuale

Deduco che arriverai puntuale

Ti chiedo una cosa: "Arriverai puntuale?"

FIGURE 2 Screenshot of a trial example

Advice: Ti do un consiglio: "Marco studia"

Vow: Lo giuro: "Marco studia"
Advice: My advice to you is: "You ought to study"

Vow: I swear: "Marco is studying"

Pictures used as stimuli varied in facial expressions and represented the AUo, $\mathrm{AU}_{2}, \mathrm{AU}_{1+4}, \mathrm{AU}_{4+5}$, or $\mathrm{AU}_{4+7}$ (see Fig. 1). A total of 20 individuals (1o females) were portrayed in the stimulus set. All pictures were greyscale, $1000 \times 500$ pixels, balanced on lightning and contrast, and aligned so that the eyes lay on a horizontal line. For each item, the shown actor varied systematically across participants, so that each participant was shown each actor twice. Pictures were selected on the basis of a norming study $(N=21)$ conducted on-line, where participants were asked to assess whether the pictures of all the actors representing all the AU s were produced by either a male or a female. Responses were on a rated scale, from o ("I'm absolutely sure she's a female") to 10 ("I'm absolutely sure he's a male"). Average rating ranged from.43 to 1.71 for female actresses and from 7.64 to 9.81 for male actors.

\subsection{Results}

Data were analysed with generalized linear mixed models by using package lme4 1.1-12 for R 3.3.2 (Bates, Mächler, Bolker, \& Walker, 2015) to account for non-independence of observations. 
The response variable - i.e., the type of speech act selected by the participants - was transformed in three separate dichotomous variables, representing the selection of the assertion, the question, or the order formulations, respectively. Given the presence of filler items, the three variables were not perfectly related, as participants could select an answer that would be neither an assertion, nor a question, nor an order. Filler item selections themselves were not analyzed. While filler items were often selected (31.6\% of responses), the type of speech act that was shown as 'filler' was not the same across items. Therefore, each specific filler speech act (e.g. a warning) occurred too rarely to be used as a dependent variable (in our example, a warning was shown among the response choices only $5 \%$ of the time, and represents only $1.1 \%$ of the total number of selections). Conversely, assertions, questions, and orders could be chosen for all items and were selected, respectively, $18.6 \%, 27.9 \%$, and $21.8 \%$ of the time.

The three response variables were fitted in three separate generalized linear mixed models using the logit link function. The AU or AUs combination shown in the stimuli was included in the models as a fixed effect, along with the gender of the actor and the interaction $\mathrm{AU}^{*}$ Actor gender. Random intercepts were included for both participants and propositional content (e.g., "Marco studia"). The only difference between the three models was the dependent variable (selecting assertion, question, or order); both fixed and random effects were the same for the three models. Table 2 reports confidence intervals of the marginal probabilities for all combination of speech acts and AUs, as plotted in Fig. 3; Table 3 reports fixed effects for the three models.

As indexed by the overlapping of confidence intervals in Table 2 - see also Fig. 3 - results showed distinct patterns for the facial expressions considered. A pattern of findings consistent with that of Domaneschi and colleagues (2017) emerged with regard to the association between the illocutionary forces of assertions, questions and orders and the correspondent AUs. The probability of selecting an assertion was far higher when the actor face displayed a blank face (AUo), the probability of selecting a question was higher for $\mathrm{AU}_{2}, \mathrm{AU}_{1+4}$, and - to a lesser extent - $\mathrm{AU}_{4+7}$ and the probability of selecting an order was higher for $\mathrm{AU}_{4+5}$ and, to a lesser extent, for $\mathrm{AU}_{4+7}$.

The effect of the gender of the actor was non-significant for the probability of selecting orders $(z=-.22, p=.83)$. However, in support our key hypothesis, the interaction actor gender $\times$ facial expression was significant for $\mathrm{AU}_{4}+5(z=2.03$, $p=.04$ ), indicating higher probability of selecting an order when the actor was male and the expression was $\mathrm{AU}_{4+5}$. 
TABLE 2 Confidence intervals of the marginal probabilities for all combination of speech acts and AUs

Speech act Action units

95\% Confidence $\quad 95 \%$ Confidence

interval (Male actor) interval (Female actress)

\begin{tabular}{|c|c|c|c|}
\hline \multirow[t]{5}{*}{ Order } & AUo (Blank face) & {$[.03, .06]$} & {$[.03, .06]$} \\
\hline & $\mathrm{AU}_{2}$ & {$[.08, .13]$} & {$[.07, .12]$} \\
\hline & $\mathrm{AU}_{1+4}$ & {$[.02, .04]$} & {$[.04, .07]$} \\
\hline & $\mathrm{AU}_{4+5}$ & {$[.55, .66]$} & {$[.42, .53]$} \\
\hline & $\mathrm{AU}_{4+7}$ & {$[.33, .44]$} & {$\left[.28, .3^{8}\right]$} \\
\hline \multirow[t]{5}{*}{ Assertion } & AUo (Blank face) & {$[.45, .55]$} & {$[.39, .49]$} \\
\hline & $\mathrm{AU}_{2}$ & {$[.13, .19]$} & {$[.11, .17]$} \\
\hline & $\mathrm{AU}_{1+4}$ & {$[.11, .17]$} & {$[.07, .12]$} \\
\hline & $\mathrm{AU}_{4+5}$ & {$[.06, .10]$} & {$[.04, .07]$} \\
\hline & $\mathrm{AU}_{4+7}$ & {$[.09, .15]$} & {$[.06, .11]$} \\
\hline \multirow[t]{5}{*}{ Question } & AUo (Blank face) & {$[.07, .12]$} & {$[.09, .14]$} \\
\hline & $\mathrm{AU}_{2}$ & {$[.32, .42]$} & {$[.40, .50]$} \\
\hline & $\mathrm{AU}_{1+4}$ & {$[.31, .40]$} & {$[.34, .44]$} \\
\hline & $\mathrm{AU}_{4+5}$ & {$[.08, .14]$} & {$[.21, .29]$} \\
\hline & $\mathrm{AU}_{4+7}$ & {$[.22, .30]$} & {$[.28, .37]$} \\
\hline
\end{tabular}
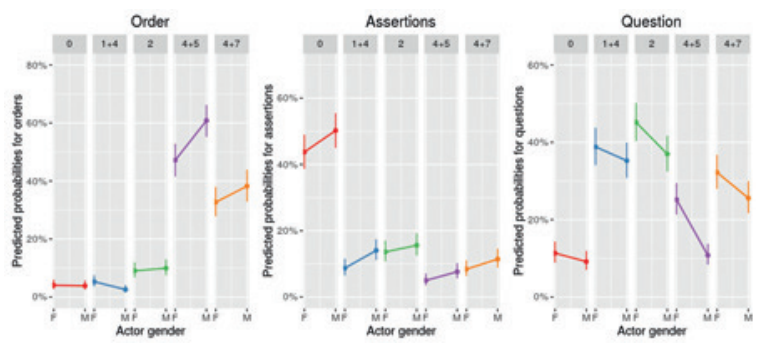

\section{FIGURE 3}

Predicted probabilities by speech act, action units and actor gender. Vertical bars represent $95 \%$ confidence intervals

Unexpectedly, results showed a significant effect of the gender of the actor on the probability of choosing an assertion $(z=2.14, p=.03)$, indicating that when the actor was a man the probability of choosing an assertion was higher than when the actor was a woman. Instead, the interaction between the actor gender and facial expression was not significant for assertions ( $z$ ranging from -.50 to $1.25, p$ ranging from.21 to.72).

With regard to questions, the effect of the gender of the actor was nonsignificant $(z=-1.26, p=.21)$, but a significant actor gender $\times$ facial expression 
TABLE 3 Fixed effects for the three models

\begin{tabular}{|c|c|c|c|c|c|}
\hline Speech act & Effect & Estimate & Std. error & $\mathrm{z}$ value & $\operatorname{Pr}(>|\mathbf{z}|)$ \\
\hline \multirow[t]{10}{*}{ Orders } & (Intercept) & -3.16 & 0.21 & -15.16 & $<.001$ \\
\hline & $\mathrm{AU}_{1+4}$ & 0.27 & 0.26 & 1.04 & 0.300 \\
\hline & $\mathrm{AU}_{2}$ & 0.85 & 0.24 & 3.60 & $<.001$ \\
\hline & $\mathrm{AU}_{4+5}$ & 3.04 & 0.21 & $14 \cdot 36$ & $<.001$ \\
\hline & $\mathrm{AU}_{4+7}$ & 2.44 & 0.21 & $11.5^{0}$ & $<.001$ \\
\hline & ActorGenderM & -0.06 & 0.28 & -0.22 & 0.827 \\
\hline & $\mathrm{AU}_{1+4}$ :ActorGenderM & -0.68 & 0.40 & -1.70 & 0.090 \\
\hline & AU 2:ActorGenderM & 0.16 & 0.33 & 0.49 & 0.624 \\
\hline & $\mathrm{AU}_{4+5}$ :ActorGenderM & 0.61 & 0.30 & 2.03 & 0.042 \\
\hline & $\mathrm{AU}_{4+7}$ :ActorGenderM & 0.30 & 0.30 & 1.00 & 0.319 \\
\hline \multirow[t]{10}{*}{ Assertions } & (Intercept) & -0.25 & 0.11 & -2.35 & 0.019 \\
\hline & $\mathrm{AU}_{1+4}$ & -2.10 & 0.17 & -12.46 & $<.001$ \\
\hline & $\mathrm{AU}_{2}$ & -1.60 & 0.15 & -10.86 & $<.001$ \\
\hline & $\mathrm{AU}_{4+5}$ & -2.69 & 0.20 & -13.59 & $<.001$ \\
\hline & $\mathrm{AU}_{4+7}$ & -2.14 & 0.17 & -12.96 & $<.001$ \\
\hline & ActorGenderM & 0.26 & 0.12 & 2.14 & 0.032 \\
\hline & $\mathrm{AU}_{1+4}$ :ActorGenderM & 0.27 & 0.22 & 1.25 & 0.213 \\
\hline & AU 2:ActorGenderM & -0.10 & 0.20 & -0.50 & 0.616 \\
\hline & $\mathrm{AU}_{4+5}$ :ActorGenderM & 0.19 & 0.26 & 0.72 & 0.470 \\
\hline & $\mathrm{AU}_{4+7}$ :ActorGenderM & 0.08 & 0.23 & 0.35 & 0.724 \\
\hline \multirow[t]{10}{*}{ Questions } & (Intercept) & -2.06 & 0.14 & -14.91 & $<.001$ \\
\hline & $\mathrm{AU}_{1+4}$ & 1.60 & 0.16 & 10.34 & $<.001$ \\
\hline & $\mathrm{AU}_{2}$ & 1.86 & 0.15 & 12.15 & $<.001$ \\
\hline & $\mathrm{AU}_{4+5}$ & 0.97 & 0.16 & 6.09 & $<.001$ \\
\hline & $\mathrm{AU}_{4+7}$ & 1.31 & 0.15 & 8.53 & $<.001$ \\
\hline & ActorGenderM & -0.24 & 0.19 & -1.26 & 0.208 \\
\hline & AU 1+4:ActorGenderM & 0.08 & 0.23 & 0.37 & 0.712 \\
\hline & AU 2:ActorGenderM & -0.10 & 0.22 & -0.46 & 0.642 \\
\hline & $\mathrm{AU}_{4+5}$ :ActorGenderM & -0.79 & 0.25 & -3.18 & 0.001 \\
\hline & $\mathrm{AU}_{4+7}$ :ActorGenderM & -0.09 & 0.23 & -0.38 & 0.702 \\
\hline
\end{tabular}


interaction was found for $\mathrm{AU}_{4+5}(z=-3.18, p=.001)$. More specifically, the interactions involving $\mathrm{AU}_{4}+5$ revealed that, while this expression was more likely to be interpreted as an order than as a question for both the genders of the actors, the probability of $\mathrm{AU}_{4+5}$ of leading to select a question was higher when the actor was female rather than male.

\section{4 \\ Discussion}

Our study aimed to address a question about the role of the gender factor in a particular case of multimodal communication: is the understanding of a speech act produced in combination with a certain facial expression affected by the gender of the speaker? Our main prediction was that perceivers would be less likely to associate the illocutionary force of the order with the corresponding facial expression $\left(\mathrm{AU}_{4+5}\right)$ when it is displayed by women rather than by men. Two key results that emerged in our study confirmed this prediction. First, consistent with Domaneschi and colleagues (2017), participants have mostly associated the illocutionary force of the order with the AU4+5, considering this AU a non-verbal IFID for the act of ordering. However, this main effect was qualified by the interaction actor gender $\times$ facial expression, that was significant for $\mathrm{AU}_{4}+5$. In particular, participants less likely associated the illocutionary force of the order with the $\mathrm{AU}_{4}+5$ when the performer of the speech act/facial expression was a woman than when he was a man. Although this expected effect provided the main evidence supporting our key hypothesis, we argue that another unexpected finding may provide further support for our expectations. That is, we observed that, while $\mathrm{AU}_{4+5}$ was mainly interpreted as an IFID of orders than of questions for both actor genders, perceivers more frequently interpreted the $\mathrm{AU}_{4+5}$ as a non-verbal IFID conveying questions than orders when the actor was female than when he was a male.

The main result which emerges from these effects is about the role of the gender factor in the interpretation of orders as jointly produced with the corresponding $\mathrm{AU}_{4+5}$. In particular, it seems that, independently of the gender of the perceiver, there is a general tendency to recognize women as less likely to perform orders as compared to men even when the act of ordering is jointly produced in combination with the facial expression (i.e., $\mathrm{AU}_{4+5}$ ) that constitutes a non-verbal marker of orders. Furthermore, in such a condition, when women are not perceived as performers of orders, their facial expression is respectively interpreted as conveying a question.

According to the Speech Act Theory, the deprivation of the freedom of a speech can occur at three different levels (Hornsby, 1993; Hornsby \& Langton, 
1998): the locutionary potential level (the possibility of saying something), the illocutionary potential level, (the possibility of performing only certain kinds of speech acts), and the perlocutionary potential level (the possibility of performing speech acts that produce actual effects on the worlds and on the others' beliefs). In most of the Western societies, in specific domains women are often deprived of this freedom at different levels. For instance, pornography has been frequently considered as an extreme example of communicative environment where women are deprived of their illocutionary potential (West, 2003; Bianchi, 2008). In fact, in pornography women are perceived as mere sexual objects (Langton, 2009) via a process of subordination that silences them and limits their illocutionary potential to a restricted range of illocutionary types, e.g. agreeing, accepting, etc.

Our claim is that data collected suggest that on-line multimodal communication is affected by a gender bias that associates different illocutionary potentials respectively to men and women. In particular, such a difference reflects a process of women's subordination.

As stated above, in the Speech Act Theory, orders and questions possess different preparatory conditions, i.e. they can be properly executed under different pragmatic circumstances. In particular, orders and questions presuppose different hierarchical relations between the interlocutors: while questions admit an equal status of the interlocutors, an order can be appropriately performed only if the speaker is in a higher hierarchical position than the addressee. Our results show that the interpretation of orders that are jointly produced with the corresponding non-verbal marker reflects a representation of women as having less power than men and as holding a subordinated hierarchical position. When considering male vs. female speakers, therefore, the perception of this hierarchical position seems to be biased by the aforementioned gender stereotypes permeating past and today's western societies. This result, therefore, might provide further support about the idea that men's higher social status is translated into men's privileges in speech (Eckert \& McConnell-Ginet, 2003).

A secondary unexpected result emerged from the present experiment regards assertions. Data collected reveal that when the performer of the speech act is male, the probability of choosing an assertion is higher than when the performer is female. Women are therefore less likely to be perceived as performers of assertions than men, independently of the non-verbal marker associated with the production of a speech act. A first potential interpretation for the effect of the gender factor on assertions might be that women are usually recognized as more tentative than men in actual speech. Lakoff (1975), for example, revealed that women tend to be less assertive than men and are more 
inclined to replace illocutionary forces like assertions that involve a demanding epistemic commitment, with, for example, tag questions. Such a result, however, cries out for further empirical investigation.

Stereotype-consistent interpretations of men's and women's speech acts might have implications for the social roles that people occupy, by contributing to maintain gender inequalities. For example, when women occupy leading positions in a working organization, their act of expressing orders may be affected by gender stereotypes and thus may be misunderstood by their subordinates. Such a process could reinforce the cultural belief that women are unable to perform orders and hold the dominant social position required for the execution of an order, reproducing in this way a gender inequality.

There are few noteworthy limitations to this work that could be addressed through future research. In particular, future studies should employ a rating task able to investigate also the degree of compatibility of the different speech acts/facial expressions depending on the genders of the actor. Moreover, it would highly relevant to take into account not only the perspective of the perceiver but also that of the producer of a speech act, in order to investigate whether the gender bias under discussion is reproduced not only in language comprehension but also in speech acts production.

\section{References}

Allwood, J., Cerrato, L., Jokinen, K., Navarretta, C., \& Paggio, P. (2005). The MUmin annotation scheme for feedback, turn management and sequencing. In Gothenburg papers in Theoretical Linguistics 92: Proceedings from The Second Nordic Conference on Multimodal Communication, pp. 91-109. Göteborg, Sweden: Göteborg University. Austin, J. (1962). How to Do Things with Words. Oxford, UK: Oxford University Press.

Bates, D., Mächler, M., Bolker, B.M., Walker, S.C. (2015). Fitting Linear Mixed-Effects Models Using lme4. Journal of Statistical Software, 67(1):1-48.

Bianchi, C., (2008). "Indexicals, Speech Acts and pornography", Analysis, 68(4), 310-316. Cuddy, A. J. C., Fiske, S.T., \& Glick, P. (2007). The BIAS Map: Behaviors from intergroup affect and stereotypes. Journal of Personality and Social Psychology, 92, 631-648.

Domaneschi, F., Passarelli, M., \& Chiorri, C. (2017). Facial expressions and speech acts: Experimental evidences on the role of the upper face as an illocutionary force indicating device in language comprehension. Cognitive Processing. Advance online publication.

Eagly, A.H. (1987). Sex differences in social behavior: A social role interpretation. Hillsdale, NJ: Erlbaum. 
Eagly, A.H., \& Steffen, V.J. (1984). Gender stereotypes stem from the distribution of women and men into social roles. Journal of Personality and Social Psychology, 46, 735-754.

Eagly, A.H., \& Wood, W. (1999). The origins of human sex differences: Evolved dispositions versus social roles. American Psychologist, 54,408-423.

Eagly, A.H., Wood, W., \& Diekman, A. (2000). Social role theory of sex differences and similarities: A current appraisal. In T. Eckes \& H.M. Trautner (Eds.), The developmental social psychology of gender (pp. 123-174). Washington, DC: Taylor \& Francis.

Eckert, P., \& McConnell-Ginet, S. (2003). Language and gender. Cambridge: Cambridge University Press.

Ekman, P., \& Friesen, W.V. (1978). Manual for the Facial Action Coding System. Palo Alto, CA: Consulting Psychologists Press.

Esposito, A., Esposito, A.M., Martone, R., Müller, V., Scarpetta, G. (Eds.) (2010). Towards Autonomous, Adaptive, and Context-Aware Multimodal Interfaces: Theoretical and Practical Issues. New York, NY \& London, UK: Springer.

Fiske, S. (1993). Controlling other people. The impact of power on stereotyping. American Psychologist, 48,621-628.

Hess, U., Adams, R.B., Jr., \& Kleck, R.E. (2004). Facial appearance, gender, and emotion expression. Emotion, 4, 378-388.

Hornsby J. (1993), "Speech Acts and Pornography” Women's Philosophy Review 10, pp. $3^{8-45}$.

Hornsby J. e Langton R. (1998), "Free Speech and Illocution" Legal Theory, 4, pp. 21-37.

Lakoff, R. (1975). Language and women's place. New York: Harper and Row.

Langton, R. (2009). Sexual solipsism: Philosophical essays on pornography and objectification. Oxford: Oxford University Press.

McGurk, H., \& MacDonald, J. (1976). Hearing lips and seeing voices. Nature, 5588(264), 746-748. doi:10.1038/264746ao.

Oertel, C., Wlodarczak, M., Edlund, J., Wagner, P., \& Gustafson, J. (2012). Gaze Patterns in Turn-Taking. In Proc. of Interspeech 2012. Portland, OR.

Pelachaud, C., Carofiglio, V., De Carolis, B., de Rosis, F., \& Poggi, I. (2002, July). Embodied contextual agent in information delivering application. In Proceedings of the first international joint conference on Autonomous agents and multiagent systems: Part 2 (pp. 758-765). New York, NY: ACM.

Pelachaud, C., Prevost, S. (1994). Sight and sound: Generating facial expressions and spoken intonation from context. In Proceedings of the 2nd Workshop on Speech Synthesis (216-219). New York, NY: New Paltz.

Plant, E.A., Hyde, J.S., Keltner, D., \& Devine, P.G. (2000). The gender stereotyping of emotions. Psychology of Women Quarterly, 24, 81-92.

Plant, E.A., Kling, K.C., \& Smith, G.L. (2004). The influence of gender and social role on the interpretation of facial expressions. Sex Roles, 51, 187-196. 
Poggi, I. \& Pelachaud, C. (2001). The Meanings of Gaze in Animated Faces. In P. McKevitt, S. Nuàllain, \& C. Mulvihill (Eds.). Language, Vision and Music. Amsterdam: John Benjamins, 2001.

Searle, J.R., Vanderveken, D. (1985). The Foundations of Illocutionary Logic. Cambridge, UK: Cambridge University Press.

Searle, J.R. (1975). Indirect speech acts. In P. Cole \& J.L. Morgan (Eds.), Syntax and Semantics, Vol. 3: Speech Acts (pp. 59-82). New York, NY: Academic Press.

West, C. 2003. The free speech argument against pornography. Canadian Journal of Philosophy, 33: 391-422. 